702 (1986)

4. C. A. Eckert, R. B. Irwin, and J. S. Smith, Met. Trans., 14B, 451 (1983).

5. "Statpak Users Guide, Computing Centre," 3rd ed., McGill University, Montreal, Que., Canada (1977).

6. P. G. Hoel, "Elementary Statistics," 2nd ed., John Wiley \& Sons Inc., New York (1966).

7. H. Ikeuchi and C. Krohn, Acta Chem. Scand., 23, 2230 (1969).

8. I. Karakaya and W. T. Thompson, J. Chem. Thermo., 18, 859 (1986).

9. A. D. Pelton and S. N. Flengas, Can. J. Chem., 47, 2283 (1969).

10. I. Karakaya and W. T. Thompson, ibid., 63, 2808 (1985); ibid., 63, 3634 (1985).

11. T. Ostvold, Ph.D. Thesis, University of Trondheim, Trondheim, Norway (1971).

12. T. Ostvold, High Temp. Sci., 4, 51 (1972).

13. W. T. Thompson, C. W. Bale, and A. D. Pelton, "F*A*C*T Facility for the Analysis of Chemical Thermodynamics," McGill University/Ecole Poly- technique, Montreal, Que., Canada (1979)

14. I. Barin, O. Knacke, and O. Kubaschewski, "Thermochemical Properties of Inorganic Substances," Springer-Verlag, Berlin, Germany (1977).

15. K. Grjotheim, J. L. Holm, and M. Rotnes, Acta Chem. Scand. 26, 3802 (1972).

16. V. E. Plyushchev, L. N. Komissarova, L. V. Meshchaninova, and L. M. Akukina, Russ. J. Inorg. Chem., 1, 220 (1956).

17. A. I. Ivanov, Izvest. Sektora Fiz-Khim. Anal. Inst. Obshchei Neorg. Khim., Akad. Nauk SSSR, 23, 197 (1953).

18. P. L. Lin, A. D. Pelton, and C. W. Bale, J. Am. Ceram. Soc., 62, 414 (1979).

19. H. Flood and S. Urnes, Z. Electrochem., 59, 834 (1955).

20. D. E. Neil, H. M. Clark, and R. H. Wiswall, J. Chem. Eng. Data, 10, 21 (1965).

21. A. D. Pelton and W. T. Thompson, Can. J. Chem., 48, $1585(1970)$.

22. S. N. Flengas and A. S. Kucharski, ibid., 49, 3971 (1971).

23. Z.-C. Wang, Trans. Faraday Soc., 86, 375 (1986).

\title{
The Influence of the Aqueous Growth Medium on the Growth Rate, Composition, and Structure of Hydrous Iridium Oxide Films
}

\author{
Peter G. Pickup' and Viola I. Birss \\ Department of Chemistry, University of Calgary, Calgary, Alberta, Canada T2N 1 N4
}

\begin{abstract}
The electrochemical growth of Ir oxide in acidic, neutral, and basic $\mathrm{LiClO}_{4}$ solutions has been investigated. Dissolution of the oxide during growth is much less in these $\mathrm{LiClO}_{4}$ solutions than in $\mathrm{H}_{2} \mathrm{SO}_{4}$ solutions, which have generally been used for Ir oxide growth, and this allows higher growth rates to be achieved. The oxide films grown in $\mathrm{LiClO}_{4}$ solutions have a greater mechanical stability and appear to be less hydrated than those grown in $\mathrm{H}_{2} \mathrm{SO}_{4}$ solutions. The empirical formula weight of the oxidized form of Ir oxide, grown in neutral $\mathrm{LiClO}_{4}$ and dried in air, was found to be $260 \pm 10$, indicative of an empirical formula of $\mathrm{IrO}_{2} \cdot 2 \mathrm{H}_{2} \mathrm{O}$. The potential at which the oxide is oxidized to an extent of one electron per Ir atom (in the oxide) has also been determined for various media. This allows the future determination of the Ir content of Ir oxide films by cyclic voltammetry.
\end{abstract}

It has been known for some years that thick hydrous iridium oxide films can be grown at iridium metal electrodes under particular potential cycling conditions (1-6). This oxide exhibits a reversible $\operatorname{Ir}(I V) /(I I I)$ oxidation state change which transforms it from a colorless insulating material (Ir(III)) to a black metallic conductor (Ir(IV)) $(7,8)$. It is, therefore, of interest, for applications in electrochromic devices. It also appears to have applications in the area of electrocatalysis, for reactions such as chlorine evolution (9) and oxygen evolution (1).

Hydrous Ir oxide has generally been grown and studied in dilute $\mathrm{H}_{2} \mathrm{SO}_{4}$, but it can be grown in a wide variety of aqueous media. Mozota and Conway (5) have shown that it can be grown in aqueous $\mathrm{Na}_{2} \mathrm{CO}_{3}$ or $\mathrm{HClO}_{4}$. Burke and Scannell (10) have reported a comprehensive study of Ir oxide in basic solutions. These authors found significant differences between films grown in $\mathrm{NaOH}$ and those grown in $\mathrm{H}_{2} \mathrm{SO}_{4}$. The base-grown films were less stable and were reported to have a less open structure than those grown in acidic solutions.

We have been interested in optimizing the conditions for Ir oxide preparation. In a previous study (11), we demonstrated that, in $0.5 \mathrm{M} \mathrm{H}_{2} \mathrm{SO}_{4}$, optimum growth rates were obtained using a potential pulsing, rather than potential scanning, method. We also explained the reported $(12,2)$ dependence of the growth rate upon the potential limits of the growth cycles (11). In the present work, the optimum aqueous growth medium was sought.

The growth of Ir oxide films in a variety of aqueous media was investigated here. We attempted to determine how the oxide growth rate, composition, and structure can be influenced by changing the growth medium. The

${ }^{1}$ Present address: Department of Chemistry, Memorial University of Newfoundland, St. John's, Newfoundland, Canada A1B $3 \times 7$. influence of the electrolyte $p H$ was of primary interest and, therefore, in most of this work, the electrolyte contained $1 M \mathrm{LiClO}_{4}$ so that the $\mathrm{pH}$ could be changed without any other significant changes occurring in the solution composition.

The composition and structure of Ir oxide films grown electrochemically in acidic solutions has been investigated previously by several groups $(3,9,13-17)$. Using weight measurements of oxide-coated Ir electrodes; McIntyre and co-workers (3) established that the main redox reaction of electrochemically grown Ir oxide is due to the Ir(IV/III) couple, although the potential at which the reaction was complete was not determined. These workers also demonstrated that the density of this oxide ( $\mathrm{ca} .2 \mathrm{~g} \mathrm{~cm}^{-3}$ ) is much less than that of anhydrous $\mathrm{IrO}_{2}\left(11.68 \mathrm{~g} \mathrm{~cm}^{-3}\right)$. However, the composition of the oxide films was not determined.

Because of the remaining uncertainty concerning the composition of electrochemically grown Ir oxide films, we have repeated the weighing experiments described by McIntyre and co-workers (3) and also have analyzed the growth medium and the oxide films for their Ir content. The combination of these two techniques allows the empirical formula weight (EFW) of the oxide to be determined without ambiguity. We have carried out these experiments for oxide films grown in different media in order to determine whether the growth medium influences the oxide composition. We have also used scanning electron microscopy to investigate structural differences in the oxide as a function of method and medium of oxide preparation.

\section{Experimental}

Electrochemistry.-All electrochemical experiments were carried out in conventional three-compartment 
glass cells, under argon at room temperature. Working electrodes were either Ir wire (99.9\%; Johnson Matthey) or foil (99.9\%; Metal Crystals and Oxides Limited, England). Details of -electrode construction and surface treatment have been given elsewhere $(11,18)$. The wire was electrochemically polished and had a roughness factor of $2.4 \pm 0.2(11)$. The foil was polished with successively finer grades of diamond paste (Micro Metallurgical Limited), down to $25 \mu \mathrm{m}$. Before each experiment, both types of electrodes were electrochemically cleaned at $c a$. $2 \mathrm{~V} v \mathrm{~s}$. SSCE in $10 \% \mathrm{H}_{2} \mathrm{SO}_{4}$ for ca. $5 \mathrm{~min}$. Occasional potential pulses into the hydrogen evolution region (e.g., $-0.7 \mathrm{~V}$ ) helped to remove oxide remaining on the electrode from the previous experiment. All electrode areas referred to in this paper are geometric areas.

Counterelectrodes were either Pt wire or gauze, and RHE. SCE, or SSCE reference electrodes were used. All potentials are quoted relative to the saturated sodium calomel electrode, SSCE (+236 $\mathrm{mV} v$ s. the NHE), used instead of the SCE to avoid frit clogging by precipitated $\mathrm{KClO}_{4}$.

An EG\&G PARC 173 potentiostat was used with a PARC 175 Universal Programmer and a PARC 179 digital coulometer. Voltammograms were recorded on Hewlett-Packard $7044 \mathrm{~A} X-Y$ or $7090 \mathrm{~A}$ recorders.

Scanning electron microscopy.-Scanning electron microscopy was performed using a Cambridge Stereoscan 2500 . The SEM samples were not coated with gold or graphite. Generally, the oxide coated electrodes were first rinsed with water and acetone, and then air dried before the SEM studies. However, a critical point drying method was used in some cases.

Critical point drying (19) is a method used to dry SEM samples with a minimum of structural damage. The sample is taken from water and soaked successively in water/ acetone mixtures of increasing acetone content $(10 \mathrm{~min}$ in $50 \%$ and $90 \%$ acetone was employed here). Finally, after soaking in pure acetone, the sample is transferred to liquid $\mathrm{CO}_{2}$, which is then heated to above its critical point and removed.

Analysis.--A Cahn 25 automatic electrobalance was used for weighing Ir foil electrodes (typically $0.2 \mathrm{~cm} \times 1$ $\times 0.005 \mathrm{~cm} ; \mathrm{ca} .10 \mathrm{mg}$ ). For electrodes weighing less than $20 \mathrm{mg}$, measurements could be made to an accuracy of $1 \mu \mathrm{g}$.

In order to determine the composition of Ir oxide films, the following procedure was used (3). The oxide was grown on a weighed Ir foil in ca. $3 \mathrm{ml}$ of the growth medium and a cyclic voltammogram was recorded at 10 $\mathrm{mV} / \mathrm{s}$. The oxide electrode was then oxidized so that approximately one electron per Ir atom in the oxide had been passed (see below), removed from the cell, washed with water and acetone, and air dried for ca. 5 to $10 \mathrm{~min}$. The oxide-coated foil was then reweighed, and in some cases, dried further and reweighed. Finally, the oxide was dissolved in $12 \mathrm{M}$ of hot $\mathrm{HCl}$ by the addition of a few drops of $30 \% \mathrm{H}_{2} \mathrm{O}_{2}$. The foil was washed with water and acetone, air dried, and reweighed. The growth medium and the solution containing the dissolved oxide were then analyzed for Ir.

Iridium analysis was accomplished by the $\mathrm{SnCl}_{2} / \mathrm{HBr}$ method (20). $\left(\mathrm{NH}_{4}\right)_{2} \mathrm{IrCl}_{6}$ (Aldrich) was used to prepare standards in the $0.4-2.0 \mathrm{ppm}$ Ir range. The reported analysis method was modified somewhat for this work. To ensure that the Ir was in the same form in all samples, the unknowns and the standards were boiled for at least $1 \mathrm{~h}$ with $\mathrm{NaCl}$ and $\mathrm{HCl}$.

Generally, $\mathrm{HCl}(12 M, 2 \mathrm{~g}), \mathrm{NaCl}(0.2 \mathrm{~g})$, and water were added to all samples to give a final volume of ca. $10 \mathrm{ml}$. The solutions were then covered and simmered on a hot plate for $c a$. $1 \mathrm{~h}$. Water was added as required to give a final volume of ca. $5 \mathrm{ml} .5 \mathrm{ml}$ of $48 \% \mathrm{HBr}$ were added to each sample and heating was continued. After $30 \mathrm{~min}, 5$ $\mathrm{ml}$ of a $25 \%$ solution of $\mathrm{SnCl}_{2} \cdot 2 \mathrm{H}_{2} \mathrm{O}$ in $48 \% \mathrm{HBr}$ were added to each sample. After a further $2 \mathrm{~min}$, the samples were rapidly cooled and diluted to $25 \mathrm{ml}$ with water. $\mathrm{Ab}$ - sorbances at $396 \mathrm{~nm}$ were measured with a Shimadzu UV-240 spectrophotometer. The average molar absorptivity for the standards was determined to be $3.0 \pm 0.3 \times$ $10^{4} M^{-1} \mathrm{~cm}^{-1}$. It was found that addition of $0.5 \mathrm{M} \mathrm{H}_{2} \mathrm{SO}_{4}$ or $1 M \mathrm{LiClO}_{4} / 0.1 \mathrm{M} \mathrm{LiOH}$ to the standards did not significantly change this value.

All chemicals were reagent grade or better (Fisher) and were used as received.

\section{Results and Discussion}

Ir oxide growth in acidic, neutral, and basic lithium perchlorate solutions.-Acidic lithium perchlorate (aq).-Figure 1 shows cyclic voltammograms of an Ir electrode in $1 M \mathrm{LiClO}_{4} / 0.1 \mathrm{M} \mathrm{HClO}$, before (- - ) and after (-) oxide growth in this solution. The oxide was grown using 600 potential pulses between -0.3 and $+1.2 \mathrm{~V}$ at 0.5 $\mathrm{Hz}$. The appearance of the Ir oxide voltammogram in the acidic $\mathrm{LiClO}_{4}$ solution is almost identical to that of Ir oxide in $0.5 \mathrm{M} \mathrm{H}_{2} \mathrm{SO}_{4}$ (2).

The principal reversible wave at $E^{\circ r}=0.56 \mathrm{~V}$ is due to the $\operatorname{Ir}$ (IV)/(III) couple and is thought to involve $\mathrm{H}^{+}$and anion (X) insertion during oxide reduction (18). Experiments carried out in $\mathrm{HF}$ solutions (18) yielded cyclic voltammograms which were very similar to that shown in Fig. 1. A chemical analysis of the contents of the film, in both the oxidized and reduced forms, showed (18) that the oxidation and reduction of Ir oxide films occurs according to reaction [1] in $\mathrm{HX}$ solutions.

$$
\begin{aligned}
\left(\mathrm{IrO}_{2} \cdot n \mathrm{H}_{2} \mathrm{O}\right)_{5}+5 e^{-} & +7 \mathrm{H}^{+}+2 \mathrm{X}^{-} \\
& =\left[\operatorname{Ir}_{5} \mathrm{O}_{3}(\mathrm{OH})_{\tau} \cdot 5 n \mathrm{H}_{2} \mathrm{O}\right]^{2+}\left(\mathrm{X}^{-}\right)_{2}
\end{aligned}
$$

Reaction [1] is also consistent with the 80 to $90 \mathrm{mV} / \mathrm{pH}$ dependence of Ir oxide reduction and oxidation, found by us and others $(10,18)$. In the $1 \mathrm{M} \mathrm{LiClO}_{4} / 0.1 \mathrm{M} \mathrm{HClO} \mathrm{H}_{4}$ solution of Fig. 1, $\mathrm{X}^{-}$is expected to be $\mathrm{ClO}_{4}^{-}$. Although this is a rather large ion, it is feasible that it can move in the pores of the oxide film, analogous to the case of $\mathrm{SO}_{4}^{2-}$, found by ESCA analysis to be present in Ir oxide films grown in sulfuric acid solutions (16).

The other features of the voltammogram of Ir oxide in acid (Fig. 1) have not been clearly assigned. It is thought that higher oxidation states of $\operatorname{Ir}(\operatorname{Ir}(V)$ or $\operatorname{Ir}(V I))$ are formed in the potential region after the main peak and before the onset of oxygen evolution at ca. $+1 \mathrm{~V}(6)$. For example, by ESCA analysis, Ir(VI) has been found to be present in thick Ir oxide films formed electrochemically in sulfuric acid solutions (16).

Neutral lithium perchlorate (aq).--Figure 2 illustrates the electrochemical growth and cyclic voltammetric behavior of Ir oxide in neutral aqueous $\mathrm{LiClO}_{4}(\mathrm{pH} \sim 6$ ). The voltammogram of the oxide in $1 \mathrm{M} \mathrm{LiClO}_{4}$ is rather complex and unusual, due to the competition between

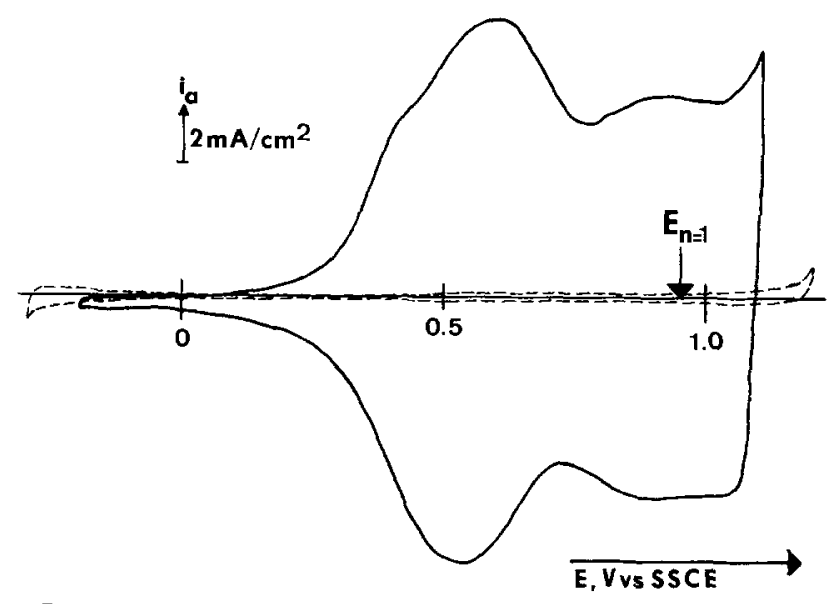

Fig. 1. Cyclic voltammograms $(100 \mathrm{mV} / \mathrm{s})$ of ir in $0.1 \mathrm{M} \mathrm{HClO} / 1 \mathrm{M}$ $\mathrm{LiClO}_{4}$, before (- - ) and after $(-) 600$ potential pulses between -0.3 and $+1.2 \mathrm{~V}$ at $0.5 \mathrm{~Hz}$ 


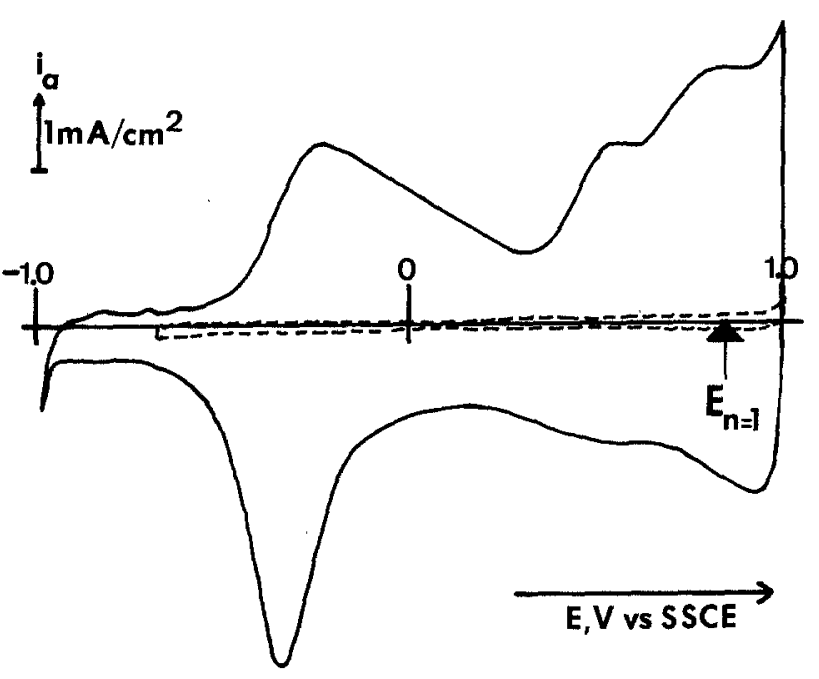

Fig. 2. Cyclic voltammograms $(100 \mathrm{mV} / \mathrm{s})$ of $\mathrm{Ir}$ in $1 \mathrm{M} \mathrm{LiClO}_{4}(\mathrm{pH} \sim$ 6), before (-- ) and after (-) 180 potential pulses between -1.2 and $+1.0 \mathrm{~V}$ ot $0.5 \mathrm{~Hz}$.

$\mathrm{H}^{+}$and $\mathrm{Li}^{+}$insertion (18) and to variations of the electrolyte $p H$ within the oxide during potential cycling $(2,10$, 18). This will be discussed in greater detail later in this paper. The main electrochemical reactions which are thought to occur in neutral $\mathrm{LiClO}_{4}$ are shown as reactions [2] and [3] (18), where the $M$ ion probably has a transient existence within the reduced form of Ir oxide (18), being replaced by $\mathrm{H}^{+}$with time

$$
\begin{gathered}
\mathrm{IrO}_{2} \cdot 2 \mathrm{H}_{2} \mathrm{O}+e^{-}+\mathrm{M}^{+}=\mathrm{M}^{+}\left[\mathrm{IrO}(\mathrm{OH})_{2} \cdot \mathrm{H}_{2} \mathrm{O}\right]^{-} \\
\mathrm{IrO}_{2} \cdot 2 \mathrm{H}_{2} \mathrm{O}+e^{--}+\mathrm{H}^{+}=\mathrm{IrO}(\mathrm{OH}) \cdot 2 \mathrm{H}_{2} \mathrm{O}
\end{gathered}
$$

Ir oxide growth in neutral solutions causes the $p H$ of the solution to gradually change because the amounts of oxygen and hydrogen evolved at the potential limits used for oxide growth are generally not equal. In order to minimize these $p \mathrm{H}$ changes, $0.01 \mathrm{M} \mathrm{Na}_{2} \mathrm{~B}_{4} \mathrm{O}_{7}$ was sometimes added to buffer the neutral $\mathrm{LiClO}_{4}$ solution. This did not appear to alter the growth or electrochemistry of the resulting oxide.

Basic lithium perchlorate (aq).-Figure 3 illustrates the growth of Ir oxide in aqueous $1 M \mathrm{LiClO}_{4} / 0.1 M \mathrm{LiOH}$. The oxide electrochemistry in this medium is similar to that obtained in $0.1 \mathrm{M} \mathrm{NaOH}$ by Burke and Scannell (10). However, the growth rate is approximately three times higher than that reported by Burke and Scannell. This is probably due to the fact that potential pulsing (11), rather than the less efficient potential scanning technique, was used for oxide growth in the present work.

The main electrochemical reaction $\left(E^{\circ}=-0.39 \mathrm{~V}\right)$ in basic media is best described by reaction [4] (18). The minor wave at $E^{\circ \prime}=-0.08 \mathrm{~V}$ has not been assigned

$$
\begin{aligned}
& \left(\mathrm{M}^{+}\right)_{3}\left[\operatorname{Ir}_{5} \mathrm{O}_{10}(\mathrm{OH})_{3} \cdot 7 \mathrm{H}_{2} \mathrm{O}\right]^{3-}+5 e^{-}+7 \mathrm{H}_{2} \mathrm{O} \\
& =\left(\mathrm{M}^{+}\right)\left[\mathrm{Ir}_{5} \mathrm{O}_{6}(\mathrm{OH})_{4} \cdot 10 \mathrm{H}_{2} \mathrm{O}^{-}+2 \mathrm{M}^{+}+7 \mathrm{OH}^{-}\right.
\end{aligned}
$$

The Composition and Structure of Ir Oxide Films.Chemical analysis.-Table I contains the results of the weighing and Ir analysis experiments. The weight measurements yield the weight of the dry oxide film in addition to the sum of the weight of Ir in the oxide, plus the Ir that dissolved during oxide growth. The chemical analysis of the solutions give the weight of Ir in the oxide and the weight of dissolved Ir. The cyclic voltammetry gives charge (or number of electrons) as a function of potential in each solution. Thus, the empirical formula weight (EFW) of the oxide can be calculated and using Faraday's law, the potential at which the oxide is oxidized to the extent of one electron per Ir atom in that solution $\left(E_{n-1}\right)$ can then be estimated. These results are also given in Table I.

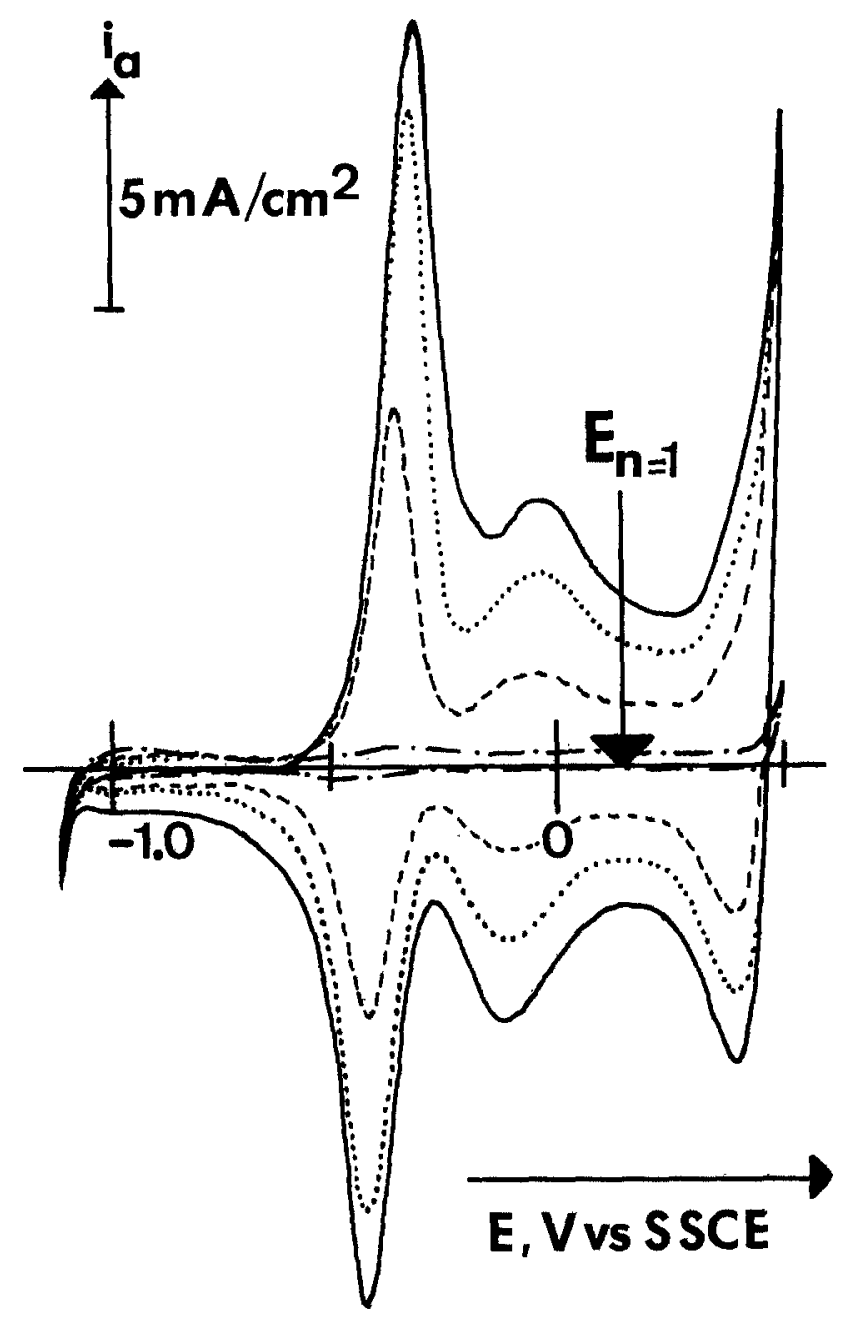

Fig. 3. Cyclic voltammograms $(100 \mathrm{mV} / \mathrm{s})$ of Ir in $0.1 \mathrm{M} \mathrm{LiOH} / 1 \mathrm{M}$ $\mathrm{LiClO}_{4}$, after $\left.\mathrm{O}(-\cdots), 450(--), 900(\cdots)\right)$, and $1350(-)$ potential pulses between -1.2 and $+0.6 \mathrm{~V}$ at $0.5 \mathrm{~Hz}$.

The sum of the two Ir analyses (Ir dissolved + Ir in oxide) should be equal to the weight loss of the Ir foil during the experiments, so that a good method of checking the accuracy of the results is available. Inspection of the data in Table I reveals that the sum of the Ir analyses generally agrees with the weight loss of the foil within experimental error $( \pm 1 \mu \mathrm{g})$. This confirms the accuracy of the weighings and analyses.

In experiment 2 , however, the sum of the Ir analyses is significantly less (by $4 \mu \mathrm{g}$ ) than the weight loss of the foil. This discrepancy may be due to loss of oxide from the foil during the rinsing, drying, and weighing procedures. SEM studies (see below) indicate that this is particularly likely for Ir oxide films grown in $0.5 \mathrm{M} \mathrm{H}_{2} \mathrm{SO}_{4}$. Extreme care should, therefore, be taken to avoid loss of oxide in this way. The error caused by oxide loss was minimized by reporting the average of the weight of Ir in the oxide from the Ir analysis of the oxide and from the weight loss of the foil minus the dissolved Ir (see footnote $d$ in Table I).

The empirical formula weights (EFW) of Ir oxide films, given in Table I, indicate that Ir oxide films grown in neutral or basic $\mathrm{LiClO}_{4}$ can be represented as $\mathrm{IrO}_{2} \cdot 2 \mathrm{H}_{2} \mathrm{O}$ $(\mathrm{EFW}=260.2)$. However, analysis of the $\mathrm{Li}^{+}$content of an Ir oxide film that had been oxidized in basic $\mathrm{LiClO}_{4}$ showed that it contained ca. $0.5 \mathrm{Li}^{+}$ion per Ir atom (18). Thus the oxide grown in this medium could be represented as $\mathrm{Li}\left[\mathrm{Ir}_{2} \mathrm{O}_{4}(\mathrm{OH})\left(\mathrm{H}_{2} \mathrm{O}\right)_{3}\right](\mathrm{EFW}=263.2$ per Ir $)$. Ir oxide films that had been oxidized in neutral $\mathrm{LiClO}_{4}$ were found to contain very little $\mathrm{Li}^{+}(18)$, although significant amounts of $\mathrm{Li}^{+}$are found in the reduced form of the oxide.

The films grown in $0.5 \mathrm{M} \mathrm{H}_{2} \mathrm{SO}_{4}$ have a significantly higher empirical formula weight than those grown in 
Table I. Weight and Ir analysis data for Ir oxide films (air dried)

\begin{tabular}{|c|c|c|c|c|c|c|c|}
\hline \multirow[b]{2}{*}{$\begin{array}{l}\text { Experiment } \\
\text { number }\end{array}$} & \multirow[b]{2}{*}{ Growth medium } & \multicolumn{2}{|c|}{ Weight $(\mu \mathrm{g})^{\mathrm{a}}$} & \multicolumn{2}{|c|}{ Ir analysis $(\mu \mathrm{g})$} & \multirow[b]{2}{*}{$\mathrm{EFW}^{\mathrm{d}}$} & \multirow[b]{2}{*}{$E_{\mathrm{n}=1}(\mathrm{~V})^{\mathrm{e}}$} \\
\hline & & Oxide & $\overline{\operatorname{Ir}^{\mathrm{b}}}$ & Dissolved $^{\mathrm{e}}$ & Oxide & & \\
\hline 1 & $0.5 \mathrm{MH}_{2} \mathrm{SO}_{4}{ }^{\prime}$ & 50 & 43 & 8 & 34 & 280 & 0.96 \\
\hline 2 & $0.5 M \mathrm{H}_{2} \mathrm{SO}_{4}{ }^{\mathrm{r}}$ & 49 & 41 & 6 & 31 & 290 & 0.93 \\
\hline 3 & $0.5 M \mathrm{H}_{2} \mathrm{SO}_{4}^{\mathrm{f}}$ & 43 & 37 & 8 & - & 280 & 0.88 \\
\hline 4 & $1.0 \mathrm{M} \mathrm{LiClO}_{4}{ }^{5}$ & 63 & 47 & 1 & - & 260 & 0.91 \\
\hline 5 & $1.0 M \mathrm{LiClO}_{4}{ }^{8}$ & 61 & 46 & 1 & 44 & 260 & 0.79 \\
\hline 6 & 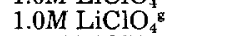 & - & - & - & 38 & - & 0.83 \\
\hline 7 & $\begin{array}{l}0.1 M \mathrm{LiOH} / \\
1.0 M \mathrm{LiClO}\end{array}$ & 60 & 45 & 1 & 44 & 260 & 0.11 \\
\hline 8 & $\begin{array}{l}0.1 \mathrm{M} \mathrm{LiOH} / \\
1.0 \mathrm{M} \mathrm{LiClO}{ }_{4}{ }^{8}\end{array}$ & - & - & - & 38 & - & 0.17 \\
\hline
\end{tabular}

$\mathrm{a} \pm 1 \mu \mathrm{g}$.

b 'Total weight loss of foil. Should be equal to weight of Ir in oxide plus weight of Ir dissolved during oxide growth.

c Ir dissolved during oxide growth.

d Empirical formula weight of oxide. Calculated from

$\mathrm{EFW}=\mathrm{AW}_{\mathrm{Ir}} \times$ weight of oxide/analyzed weight of Ir in oxide

or

$\mathrm{EFW}=\mathrm{AW}$ Ir $\times$ weight of oxide/(weight loss of foil - weight Ir dissolved).

Where both calculations were possible, the average is given. Estimated error is $\pm 10 . A W_{\mathrm{Ir}}$ is the atomic weight of Ir $=192$.

e Potential (vs. SSCE) at which the oxide is oxidized to extent of one electron per Ir atom in oxide film.

${ }^{f}$ Oxide grown by potential pulsing $(0.5 \mathrm{~Hz})$ between -0.26 and $+1.24 \mathrm{~V}$ for $30 \mathrm{~min}$.

${ }^{\mathrm{g}}$ Oxide grown by potential pulsing $(0.5 \mathrm{~Hz})$ between -1.20 and $+1.20 \mathrm{~V}$ for $30 \mathrm{~min}$.

$\mathrm{LiClO}_{4}$ solutions and are, therefore, probably more hydrated, e.g., $\mathrm{IrO}_{2} \cdot 3 \mathrm{H}_{2} \mathrm{O}(\mathrm{EFW}=278.2)$. It should be noted that loosely attached water present initially in small pores or voids within the oxide may have been removed by the acetone rinsing procedure, prior to the heating steps. The extra weight in $\mathrm{H}_{2} \mathrm{SO}_{4}$ solutions may also be due to the presence of $\mathrm{SO}_{4}{ }^{2-}$, which has been detected in Ir oxide films, grown in $\mathrm{H}_{2} \mathrm{SO}_{4}$ solutions, by several research groups $(2,16)$.

The data in Table I was obtained using oxide films which were dried in air for 5 to $10 \mathrm{~min}$. Clearly, most of the adhering water and any water in the pores of the oxide film is lost rapidly from the oxide under these mild drying conditions. Some further weight measurement experiments were carried out in order to determine whether the remaining water could be removed. The results of these experiments are shown in Table II.

Drying in air for longer periods produces some further weight loss and drying in a vacuum at an elevated temperature causes even further weight loss. The vacuumdried films were found to be very difficult to remove from the underlying Ir foil. They could be removed electrochemically at $+2 \mathrm{~V}$ in $10 \% \mathrm{H}_{2} \mathrm{SO}_{4}$ but the dislodged oxide did not dissolve and therefore Ir analysis of the oxide could not be performed. However, the data in Table I indicates that the weight of Ir in an oxide film corresponds to $78 \pm 2 \%$ and $97 \pm 1 \%$ of the weight loss of the foil, in $0.5 \mathrm{M} \mathrm{H}_{2} \mathrm{SO}_{4}$ and $1 M \mathrm{LiClO}_{4}$, respectively. The empirical formula weights in Table II were calculated on this basis (see footnote a in Table II and $d$ in Table I).

It is clear from Table II that Ir oxide films grown in either $0.5 \mathrm{M} \mathrm{H}_{2} \mathrm{SO}_{4}$ or $1 M \mathrm{LiClO}_{4}$ can be dehydrated to give $\mathrm{IrO}_{2}(\mathrm{FW}=224)$. The oxide grown in $0.5 \mathrm{M} \mathrm{H}_{2} \mathrm{SO}_{4}$ can be dried to $\mathrm{IrO}_{2} \cdot 2 \mathrm{H}_{2} \mathrm{O}(\mathrm{FW}=260)$ at room temperature in air and to $\mathrm{IrO}_{2}$ in a vacuum at $>70^{\circ} \mathrm{C}$. These results indicate that the $\mathrm{SO}_{4}{ }^{2-}$ content of this oxide must be less than one ion per six IrO ${ }_{2}$ units. Analysis of the $\mathrm{F}^{-}$content of Ir oxide films which had been oxidized in $0.2 \mathrm{M} \mathrm{HF}$ also indicated that anion incorporation into the oxidized form of the oxide was minimal (18).

Based upon the results in Tables I and II, it can be stated that there is little difference in the composition of Ir oxide films grown in the different media used in this work, although the films grown in $0.5 \mathrm{M} \mathrm{H}_{2} \mathrm{SO}_{4}$ may be slightly more hydrated.

The $E_{n=1}$ results in Table I are extremely useful because the amount of Ir in an Ir oxide film can now be determined by cyclic voltammetry. In the past, the relative quantity of Ir present in an Ir oxide film has been estimated from the charge density passed during a voltammetric sweep $(3,5,6,11)$, but an absolute determination has not been possible. In $0.5 \mathrm{M} \mathrm{H}_{2} \mathrm{SO}_{4}$, the charge density integrated up to $+1.30 \mathrm{~V} v s$. $\operatorname{RHE}\left(q_{0 x, 1.3}\right)$ was used as a relative measure of the oxide quantity (11). This upper potential for the integration was chosen somewhat arbitrarily because $E_{\mathrm{n}=1}$ had not been determined at that time.

Ir oxide film quantities can now be expressed in moles of Ir per unit electrode area $(\Gamma)$ by using Eq. [1]. It is assumed here that all of the Ir sites in the film are electroactive, particularly in slow potential sweep experiments

$$
\Gamma=q_{\mathrm{ox}, \mathrm{n}-1} / \mathbf{F}
$$

$q_{0 x, \mathrm{n}=1}$ is the charge density passed during a slow potential sweep from the onset of oxidation of the oxide (e.g., $\sim 0.1 \mathrm{~V}$ in Fig. 1) to $E_{n=1} . \Gamma$ is independent of the medium in which the voltammogram is recorded and so a comparison of $E_{\mathrm{n}=1}$ in different media is now possible. The average $E_{\mathrm{n}=1}$ values from Table I are $0.92 \pm 0.04,0.84 \pm 0.06$, and $0.14 \pm 0.04 \mathrm{~V}$, for Ir oxide in $0.5 \mathrm{M} \mathrm{H}_{2} \mathrm{SO}_{4}, 1 M \mathrm{LiClO}_{4}$, and $0.1 M \mathrm{LiOH} / 1 M \mathrm{LiClO}_{4}$, respectively. $E_{\mathrm{n}=1}$ for Ir oxide in $0.1 M \mathrm{HClO}_{4} / 1 \mathrm{M} \mathrm{LiClO}_{4}$ was estimated to be $0.95 \mathrm{~V}$ from an experiment in which an Ir oxide coated electrode was grown in the solution and then transferred to a solution for which the $E_{\mathrm{n}=1}$ is known $\left(0.1 \mathrm{M} \mathrm{LiOH} / 1 \mathrm{M} \mathrm{LiClO}_{4}\right)$.

Table II. Weight dato for Ir oxide films as a function of drying method

\begin{tabular}{|c|c|c|c|c|c|c|c|}
\hline \multirow[b]{2}{*}{ Growth medium } & \multicolumn{3}{|c|}{$\underset{(\mu \mathrm{g})}{\text { Weight of oxide }}$} & \multirow{2}{*}{$\begin{array}{l}\text { Weight } \\
\text { loss of } \\
\text { foil } \\
(\mu g)\end{array}$} & \multicolumn{3}{|c|}{$\begin{array}{l}\text { Empirical } \\
\text { formula } \\
\text { weight }^{\star}\end{array}$} \\
\hline & $\mathrm{A}$ & B & $\mathrm{C}$ & & A & B & $\mathrm{C}$ \\
\hline $\begin{array}{l}0.5 M \mathrm{H}_{2} \mathrm{SO}_{4}{ }^{\mathrm{b}} \\
0.5 M \mathrm{H}_{2} \mathrm{SO}_{4} \mathrm{~b} \\
0.5 M \mathrm{H}_{2} \mathrm{SO}_{4}{ }^{\mathrm{b}, c} \mathrm{c} \\
1.0 M \mathrm{LiClO}_{4} / \\
0.01 M \mathrm{Na}_{2} \mathrm{~B}_{4} \mathrm{O}_{7}{ }^{\mathrm{d}}\end{array}$ & $\begin{array}{r}55 \\
43 \\
222 \\
123 \\
\\
\text { A. } \mathrm{Dr} \\
\text { B. } \mathrm{Dr} \\
\text { C. } \mathrm{Dr} \\
\mathrm{M} \\
\mathrm{M} \\
\mathrm{p}\end{array}$ & $\begin{array}{l}- \\
215 \\
111 \\
\text { ried } \\
\text { ried } \\
\text { ried i } \\
\text { taxim } \\
\text { baren }\end{array}$ & $\begin{array}{l}51(60) \\
40(70) \\
185(90) \\
104(90) \\
\\
\text { for } 5-10 \mathrm{~m} \\
\text { for }>16 \mathrm{~h} \\
\text { n vacuum } \\
\text { lum temp } \\
\text { theses. }\end{array}$ & $\begin{array}{r}46 \\
37 \\
194 \\
88 \\
\\
\text { n in air. } \\
\text { n air. } \\
\text { at } 60^{\circ}-90^{\circ} \\
\text { rature }\left({ }^{\circ} \mathrm{C}\right.\end{array}$ & $\begin{array}{l}280 \\
280 \\
270 \\
270\end{array}$ & $\begin{array}{l}\overline{-} \\
260 \\
250\end{array}$ & $\begin{array}{l}260 \\
260 \\
230 \\
230\end{array}$ \\
\hline
\end{tabular}

a Calculated by assuming that the weight of Ir in the oxide is $78 \%$ of the foil weight loss in $0.5 \mathrm{M} \mathrm{H}_{2} \mathrm{SO}_{4}$ and $97 \%$ in $1 M \mathrm{LiClO}_{4}$ (i.e., from data in Table I).

b Oxide grown by potential pulsing $(0.5 \mathrm{~Hz})$ between -0.26 and $+1.24 \mathrm{~V}$ for $30 \mathrm{~min}$.

' Larger electrode. Weighings on Mettler Micro Gramatic balance to $\pm 5 \mu \mathrm{g}$.

d Oxide grown by potential pulsing $(0.5 \mathrm{~Hz})$ between -1.20 and

$+1.10 \mathrm{~V}$ for $60 \mathrm{~min}$ 
The positions of these $E_{n=1}$ potentials on the voltammograms shown in Fig. 1-3 have been marked on the figures. It is clear that at all $p H$ 's, Ir oxide can be reversibly oxidized to an extent of greater than one electron per Ir. It can also be seen that the oxidation of Ir oxide from Ir(III) to $\operatorname{Ir}(I V)$ does not occur as a single peak and that the generation of higher oxidation states of $\operatorname{Ir}(\operatorname{Ir}(\mathrm{V})$ or $\operatorname{Ir}(\mathrm{VI}))$ may actually commence before the oxide has been completely transformed to the Ir(IV) form. Finally, it should be noted that, if the assumption that each Ir site in the oxide provides one electron (Eq. [1]) had been unjustified, the $E_{n=1}$ values would either have been very low, i.e., only a small fraction of the total oxide charge would have passed at $E_{n-1}$, or excessively high, i.e., positive of the potential for oxygen evolution. The fact that $E_{\mathrm{n}=1}$ appears at a reasonable point in the cyclic voltammograms supports the initial hypothesis of the involvement of one electron per Ir site in the oxide.

Scanning electron microscopy.-Figure 4 shows several scanning electron micrographs of some electrochemically grown Ir oxide films formed on polished Ir surfaces. The film shown in Fig. $4 \mathrm{~A}$ was grown in $0.5 \mathrm{M}$ $\mathrm{H}_{2} \mathrm{SO}_{4}$ and was dried in air after soaking in water for 10 $\mathrm{min}$. This film is extensively cracked and shows poor mechanical stability, as seen by the fact that flakes of oxide have fallen from the electrode (top right-hand area of
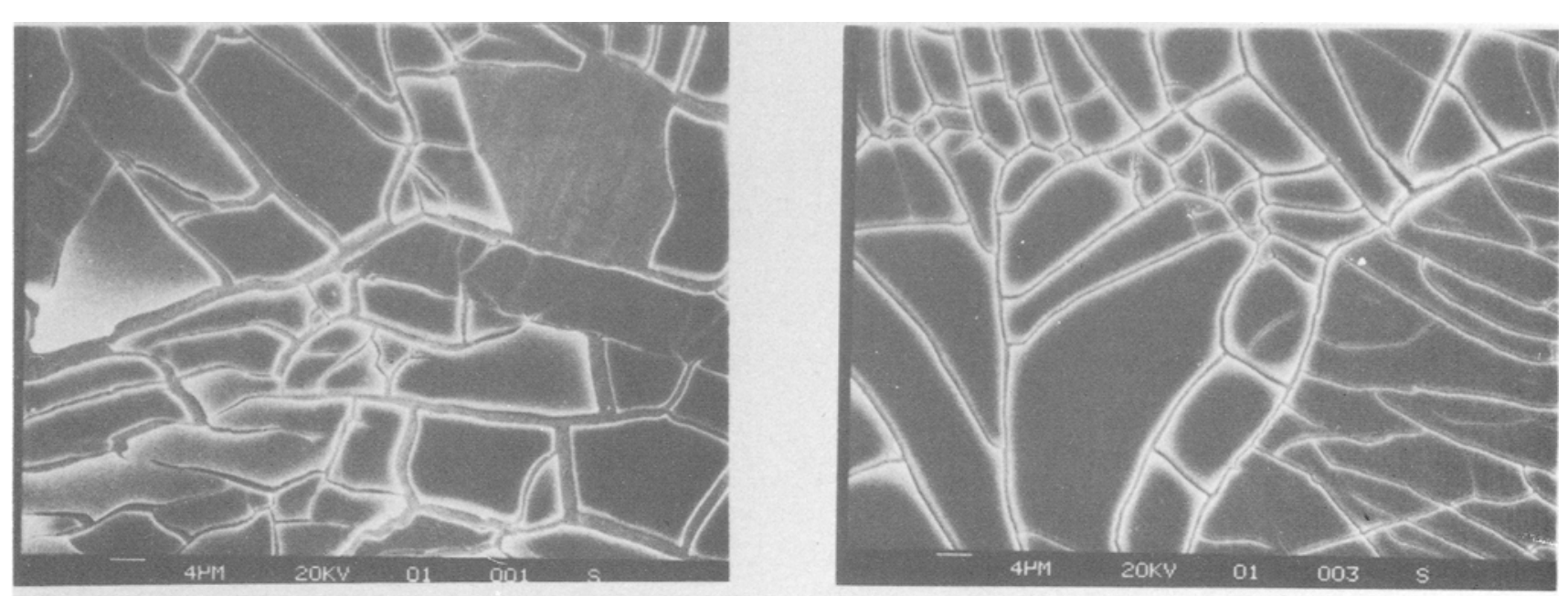

Fig. 4A). This type of structure has been reported previously by Mozota and Conway (9).

The film shown in Fig. $4 \mathrm{~B}$ was grown under the same conditions as the film in Fig. 4A. However, this film was subsequently dried by the critical point method (see Experimental section). It can be seen that the use of this drying method leads to a similar cracked structure, although the cracks (Fig. 4B) are significantly narrower than those in Fig. 4A, indicative of less shrinkage of the oxide film. Also, no loss of flakes of oxide was seen by the SEM examination (Fig. 4B), and, hence, the film is probably more adherent than that shown in Fig. 4A. The fact that this critical-point dried film is still cracked probably indicates that the cracking occurs during oxide growth, as reported by Mozota and Conway (9). However, the oxide can obviously suffer further damage during sudden drying.

The film shown in Fig. $4 \mathrm{C}$ was grown in aqueous $1 \mathrm{M}$ $\mathrm{LiClO}_{4} / 0.01 M \mathrm{Na}_{2} \mathrm{~B}_{4} \mathrm{O}_{7}$ and dried in air after soaking in water for $10 \mathrm{~min}$. The degree of cracking for this film is significantly less than that of the film grown in $0.5 \mathrm{M}$ $\mathrm{H}_{2} \mathrm{SO}_{4}$ (Fig. 4A). This indicates that structural differences must exist between the films grown in the two different media. The SEM photographs cannot reveal these differences, but the results of the chemical analyses given in the previous section (Tables I and II) may provide some clues. The oxide grown in $0.5 \mathrm{M} \mathrm{H}_{2} \mathrm{SO}_{4}$ appears to retain

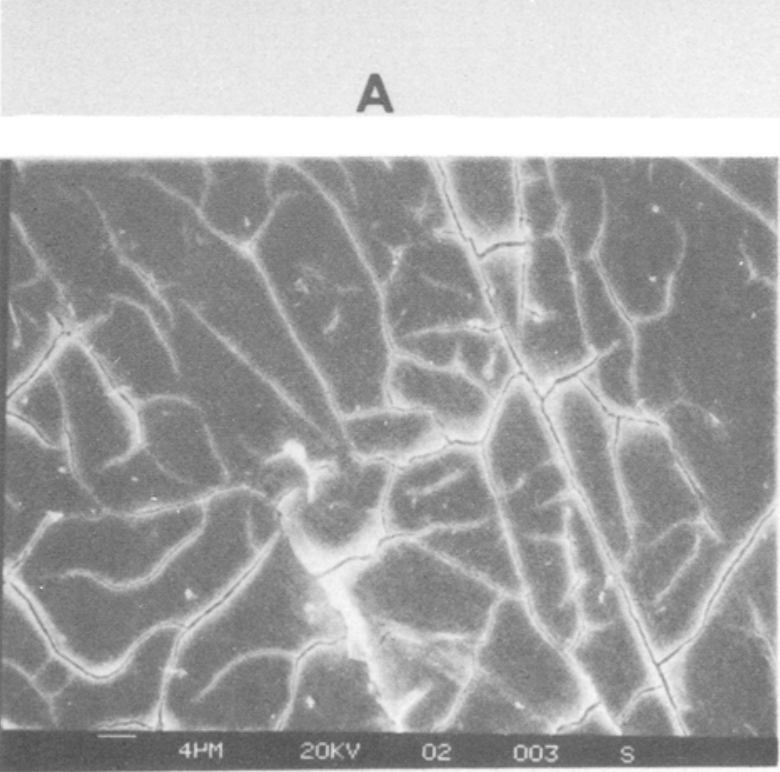


more water than the oxide grown in $1 \mathrm{M} \mathrm{LiClO}_{4}$. Perhaps the acid-grown oxide has a more open and hydrated structure that is more susceptible to shrinkage and cracking during drying. It should be recalled that water which could have been present within micropores of the oxide may have been removed by acetone rinsing. If this water had also been monitored, it is possible that the acid-grown oxides would have yielded a significantly greater water content than those grown in neutral solutions. It should also be noted that the growth of films in acid solutions resulted in significantly higher dissolution rates. Oxide dissolution could also be linked to loss of mechanical strength of the oxide.

One aim of this SEM study was to measure the porosity of anodic Ir oxide films. However, no higher magnification microstructure than that shown in Fig. 4 could be resolved. It must be concluded that, in all cases, the pores in the oxide are less than $50 \mathrm{~nm}$ in diameter.

SEM is a useful technique for measuring the thickness of films. Figure $4 \mathrm{D}$ shows a cross-sectional view of an oxide-coated Ir surface, formed in $0.5 \mathrm{M} \mathrm{H}_{2} \mathrm{SO}_{4}$. The film contained $6.6 \times 10^{-7} \mathrm{~mol} \mathrm{~cm} \mathrm{~cm}^{-2}$ of Ir and was about 0.8 to $0.9 \mu \mathrm{m}$ thick. This yields a useful relationship between oxide quantity and film thickness of ca. $7.8 \times 10^{-7} \mathrm{~mol}$ $\mathrm{cm}^{-2}$ of Ir oxide per micron of film, or a film density of $\mathrm{ca}$. $2.0 \mathrm{~g} \mathrm{~cm}^{-3}$ (assuming an EFW of 260). This density is in excellent agreement with the value of ca. $2.0 \mathrm{~g} \mathrm{~cm}^{-3} \mathrm{re}-$ ported by McIntyre and co-workers (3).

Effect of potential limits on Ir oxide growth rates.-In order to build up a thick hydrous oxide film at Ir, repeated potential cycling is required and in each cycle, only half a monolayer of Ir can be converted to hydrous oxide (11). Figure 5 shows the effect on the oxide growth rate of using different potential cycling limits in acidic, neutral, and basic $\mathrm{LiClO}_{4}$ solutions. The results are similar to those obtained in other media $(2,5,10,12)$ and indicate that our model for $\mathrm{Ir}$ oxide growth in $0.5 \mathrm{M} \mathrm{H}_{2} \mathrm{SO}_{4}$ (11) may be applicable at all $p H$ 's.

In this model, hydrous oxide growth commences when a thin compact oxide initially grows (at potentials above ca. $+0.3 \mathrm{~V} v s$. SSCE in $0.5 \mathrm{M} \mathrm{H}_{2} \mathrm{SO}_{4}$ ) on the Ir metal surface and the outer layer of this oxide becomes hydrated (hydrated surface layer) at potentials greater than ca. $+1 \mathrm{~V}$ in $0.5 \mathrm{M} \mathrm{H}_{2} \mathrm{SO}_{4}$. The inner compact oxide can be electrochemically reduced to Ir metal but the hydrated surface layer cannot be electrochemically reduced in the accessible range of potential and, therefore, as the potential is continuously cycled, it accumulates on the electrode surface as a film of hydrous oxide. If the lower potential limit is insufficient to reduce the inner compact oxide, then the hydrated surface layer remains bound to it and is not released into the hydrous oxide layer.

The general trends shown in Fig. 5 can be easily understood in terms of this model. Thus, the increase in growth rate as the lower potential limit $\left(E_{-}\right)$is decreased is due to the increased extent of reduction of the inner compact oxide. This leads to an increase in the amount of new hydrated surface layer which can be generated and released into the bulk hydrous oxide during each cycle of the potential. The increase in growth rate as the upper potential limit $\left(E_{+}\right)$is raised is due to an increase in the quantity of the hydrated surface layer that is formed in each cycle. The growth of oxide per cycle never exceeds the limit of half a monolayer of Ir metal (ca. $2.8 \times$ $10^{-9} \mathrm{~mol} \mathrm{~cm}^{-2}$ ), as predicted by the model (11).

An understanding of the details of Fig. 5 requires consideration of two further aspects. These are (i) the effect of $p \mathrm{H}$ on the growth of the hydrated surface layer and the reduction of the inner compact oxide and (ii) the $p H$ changes in the solution close to the electrode caused by the Ir oxide electrochemistry and by $\mathrm{H}_{2}$ and $\mathrm{O}_{2}$ evolution.

Oxide growth and reduction will occur at lower potentials ( $v s$. the $p \mathrm{H}$ independent $\mathrm{SSCE}$ ) as the $p \mathrm{H}$ is increased (21). Oxidation of the oxide and $\mathrm{O}_{2}$ evolution will both cause the $p H$ close to the electrode to decrease, while oxide reduction and $\mathrm{H}_{2}$ evolution will cause it to increase (22). The fixed potential limits of $E_{-}=-1.2 \mathrm{~V}$ and $E_{+}=+1.5 \mathrm{~V} v$ s. SSCE used to obtain the data for Fig. 5 are

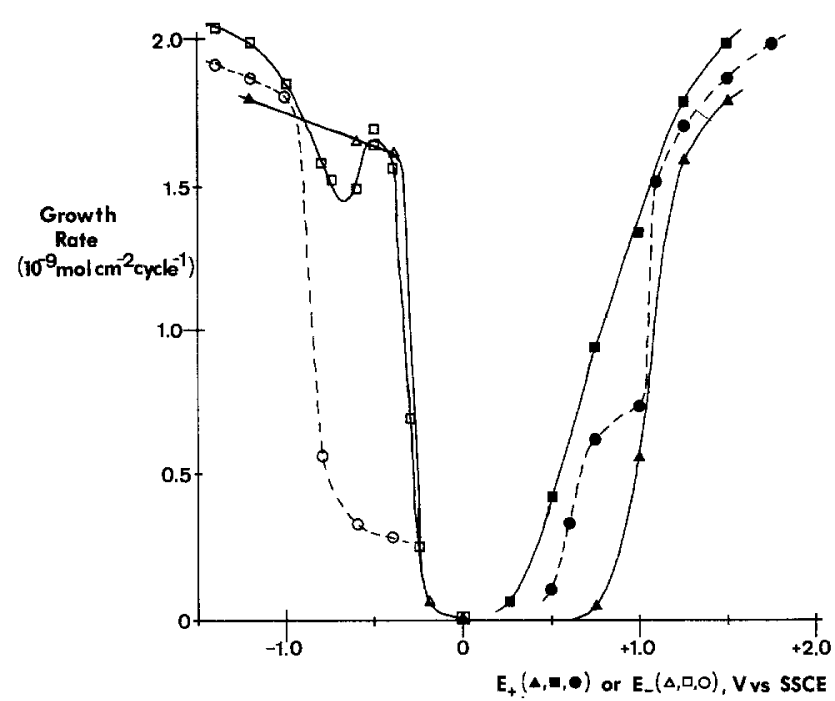

Fig. 5. Average Ir oxide growth rates over 150 potential pulses at

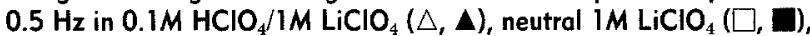
and $0.1 \mathrm{M} \mathrm{LiOH} / 1 \mathrm{M} \mathrm{LiClO} \mathrm{O}_{4}(\mathrm{O}, \mathrm{O})$ as a function of the potential limits. The open points represent experiments where $E_{+}$was constant at $+1.5 \mathrm{~V}$, while $E_{-}$was varied. For the solid points, $E_{-}$was $-1.2 \mathrm{~V}$ and $E_{+}$ was varied.

sufficient to cause extensive $\mathrm{H}_{2}$ and $\mathrm{O}_{2}$ evolution, respectively, at all $p H$ 's used.

The data for acidic $(p H=1) \mathrm{LiClO}_{4}$ in Fig. 5 is the most straightforward. The $E_{+}$data $(\boldsymbol{\Delta})$ represents the rate of growth of the oxide at a constant $E_{-}$value of $-1.2 \mathrm{~V}$ but with a varying $E_{+}$. This is equivalent to altering the extent of formation of the hydrated surface layer as a function of the anodic potential limit. The $E_{-}$data $(\Delta)$ represents the rate of oxide growth when $E_{+}$was constant at $1.5 \mathrm{~V}$ and $E_{-}$was varied. This can be considered as a study of the rate of reduction of the inner compact oxide as a function of $E$.

The $E_{-}$for basic $\mathrm{LiClO}_{4}(O)$ represents the rate of inner compact oxide reduction at $p H \sim 13$, except for $E_{-}$values more positive than $-0.8 \mathrm{~V}$, where the oxide growth rate (E inner oxide reduction rate) is higher than would be expected at $p \mathrm{H} \sim 13(21)$. The reason for this is that the $\mathrm{H}^{+}$generated at $E_{+}(+1.5 \mathrm{~V})$ in the previous cathodic pulse causes the $p \mathrm{H}$ close to the electrode to be significantly lower than 13 at the beginning of the cathodic pulse. Thus some inner compact oxide reduction can occur at $E_{-}>-0.8 \mathrm{~V}$, before the solution $p \mathrm{H}$ equilibrates.

A similar argument can be applied to the $E_{-}$data for neutral $\mathrm{LiClO}_{4}(\square)$. For $E_{-}>-0.5 \mathrm{~V}$, the $\mathrm{H}^{+}$generated at $E_{+}$maintains the solution $p H$ close to the electrode at a low value (i.e., -1 ) and so the hydrous oxide growth rate ( $\equiv$ inner compact oxide reduction rate) is the same as for acidic $\mathrm{LiClO}_{4}$. However, for $E_{-}<-0.5 \mathrm{~V}$, the $\mathrm{OH}^{-}$generated by oxide reduction and $\mathrm{H}_{2}$ evolution at $E_{\text {. inhibits }}$ inner compact oxide reduction and, therefore, the hydrous oxide growth rate $v s . E_{-}$plot goes through a minimum as it switches from acidic to basic behavior.

The $E_{+}$data for neutral $\mathrm{LiClO}_{4}(\mathbb{C})$ reflects the rate of hydrated surface layer growth in weakly basic solutions because the solution close to the electrode is made basic at $E_{-}$. Hydrous oxide growth, therefore, occurs at significantly lower values of $E_{+}$than in acid.

The $E_{+}$data for basic $\mathrm{LiClO}_{4}(\mathbf{O})$ is anomalous as it falls between the acidic and neutral data. Hydrated surface layer formation is expected to occur at lower potentials as the $\mathrm{pH}$ is increased and so hydrous oxide growth should occur at lower values of $E_{+}$as the $\mathrm{pH}$ is increased. A clue to the origin of this anomaly lies in the "step" in the $E_{+}$data for basic $\mathrm{LiClO}_{4}$ at potentials between +0.75 and $+1.0 \mathrm{~V}$. This step corresponds to the potential region in the voltammogram between oxygen evolution from a basic solution $(\sim 0.8 \mathrm{~V})$ and oxygen evolution from neutral $\mathrm{H}_{2} \mathrm{O}(E>1.2 \mathrm{~V})$. This indicates that oxygen evolution, i.e., the protons released by oxygen evolution, enhances hydrous oxide growth in some way in basic solutions. 
Burke and Scannell (10) have reported that the release of protons from the oxide at $E_{+}$enhances hydrous oxide growth and that acidification of the solution close to the electrode is probably necessary for hydrous oxide growth to occur in base. The present results confirm the enhancement of oxide growth by proton release at $E_{+}$in basic media. However, the $E_{+}$data for neutral $\mathrm{LiClO}_{4}$ solutions clearly show that the solution near the electrode does not need to become acidic. With $E_{-}=-1.2 \mathrm{~V}$ and $E_{+}$ $=+0.5 \mathrm{~V}$, the $\mathrm{OH}^{-}$produced at $E_{-}$would be sufficient to maintain a high $p \mathrm{H}$ close to the electrode. However, hydrous oxide growth still occurs under these conditions (Fig. 5). Thus, it appears that the low hydrous oxide growth rates in basic media are due to suppression of oxide growth by high $\mathrm{OH}^{-}$concentrations. It may be that the oxide begins to dissolve when the $p H$ is very high (10).

For $E_{-}<-1.0 \mathrm{~V}$ and $E_{+}>+1.25 \mathrm{~V}$, the data in Fig. 5 is the same, within experimental error, for acidic, neutral, and basic solutions. These potentials are sufficient in magnitude to rapidly reduce the inner compact oxide (at negative potentials) and produce the hydrated surface layer (at positive potentials) at any $p \mathrm{H}$. The $p H$ changes close to the electrode caused by $\mathrm{H}_{2}$ and $\mathrm{O}_{2}$ evolution at these potentials probably swamp any effects due to the $\mathrm{pH}$ of the bulk solution.

An important feature of the data in Fig. 5 is that the oxide growth rate continues to increase as $E_{+}$is raised above $1 \mathrm{~V}$. In $0.5 \mathrm{M} \mathrm{H}_{2} \mathrm{SO}_{4}$ or $0.1 \mathrm{M} \mathrm{NaOH}$ (i.e., no $\mathrm{Li}^{+}$present), the growth rate rises to a maximum at ca. $1.25(5,12)$ or $0.55 \mathrm{~V}(10)$, respectively, and then decreases sharply as $E_{+}$reaches values at which significant oxygen evolution occurs. This is probably due to the increased rate of dissolution of the oxide once $\mathrm{O}_{2}$ evolution commences $(3,5$, 12). Similar maxima have also been reported for $\mathrm{Ir}$ oxide growth in $0.5 M \mathrm{Na}_{2} \mathrm{CO}_{3}$ and $1 \mathrm{M} \mathrm{HClO}_{4}$ (5).

The results of the chemical analyses given in Table I show that Ir oxide dissolution during growth in neutral or basic $\mathrm{LiClO}_{4}$ solutions is very low and is much less than in $0.5 \mathrm{M} \mathrm{H}_{2} \mathrm{SO}_{4}$. This then explains the above difference and supports the hypothesis that the apparent decrease in oxide growth rate at high potentials in some media is due to oxide dissolution. The reason for the low solubility of Ir oxide in the $\mathrm{LiClO}_{4}$ solutions is not clear.

Comparison of growth rates in different aqueous solutions.-Oxide growth rates in the various media are shown in Fig. 6 as a function of the number of cycles of potential. In all solutions, the growth rate declines significantly as the oxide thickens (after more cycles). This is presumably due to the uncompensated resistance of the hydrous oxide film, which increases as the film thickens. The effect is greater in the $\mathrm{LiClO}_{4}$ solutions than in $0.5 \mathrm{M} \mathrm{H}_{2} \mathrm{SO}_{4}$. This is probably due to the lower conductivity of the $\mathrm{LiClO}_{4}$ solutions and possibly a lower porosity of Ir oxide films grown in $\mathrm{LiClO}_{4}$ solutions. The approximate theoretical limit shown in Fig. 6 corresponds to one monolayer of $\mathrm{IrO}_{2}$, which appears to be the maximum amount that can become hydrated in a single cycle of potential (11).

The results in Fig. 6 clearly show that higher oxide growth rates can be achieved in $\mathrm{LiClO}_{4}$ solutions than in $0.5 \mathrm{M} \mathrm{H}_{2} \mathrm{SO}_{4}$. It should be noted that the growth rates in Fig. 6 for $0.5 \mathrm{M} \mathrm{H}_{2} \mathrm{SO}_{4}(\mathrm{O})$ are the optimum values (i.e., optimized potential limits) for cycling at $0.5 \mathrm{~Hz}$, whereas the growth rates at $0.5 \mathrm{~Hz}$ for the $\mathrm{LiClO}_{4}$ solutions

iil) could presumably be increased even further by raising $E_{+}$(see Fig. 5).

The primary reason for the higher oxide growth rates in the $\mathrm{LiClO}_{4}$ solutions is that higher values of $E_{+}$can be used. In $0.5 \mathrm{M} \mathrm{H}_{2} \mathrm{SO}_{4}$, the oxide growth rate begins to decrease at $E_{+}$greater than $+1.25 \mathrm{~V}$ because of dissolution of the oxide at these $E_{+}$values (see above). If the optimum oxide growth conditions at $0.5 \mathrm{~Hz}$ in $0.5 \mathrm{M} \mathrm{H}_{2} \mathrm{SO}_{4}$ are used for acidic $\mathrm{LiClO}_{4}$, then very similar growth rates to those in $0.5 \mathrm{M} \mathrm{H}_{2} \mathrm{SO}_{4}(\mathrm{O})$ are obtained [Fig. 6 ( $\square$ )]. The only difference is a more rapid decrease in growth rates with increasing film thickness for the $\mathrm{LiClO}_{4}$ solution $v s$. $0.5 \mathrm{M} \mathrm{H}_{2} \mathrm{SO}_{4}$, as discussed above.

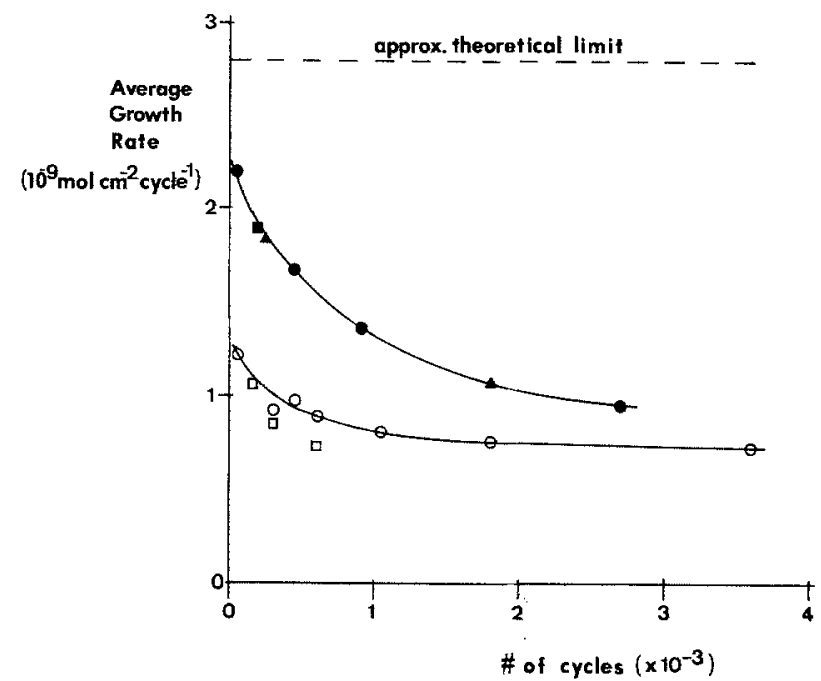

Fig. 6. Average growth rates as a function of the number of growth cycles for Ir oxide growth in various media using potential pulsing at $0.5 \mathrm{~Hz}$.

(O) $1 \mathrm{M} \mathrm{LiClO}, E_{-}=-1.4 \mathrm{~V}, \mathrm{E}_{+}=+1.6 \mathrm{~V}$.

(A) $0.1 \mathrm{M} \mathrm{LiOH} / 1 \mathrm{M} \mathrm{LiClO}, E_{-}=-1.4 \mathrm{~V}, E_{+}=+1.6 \mathrm{~V}$

(D) $0.1 \mathrm{M} \mathrm{HClO} / 1 \mathrm{M} \mathrm{LiClO}_{4}, E_{-}=-1.4 \mathrm{~V}, E_{+}=+1.6 \mathrm{~V}$

(O) $0.5 \mathrm{M} \mathrm{H}_{2} \mathrm{SO}_{4}, E_{-}=-0.26 \mathrm{~V}, \mathrm{E}_{+}=+1.24 \mathrm{~V}$.

(口) $0.1 \mathrm{M} \mathrm{HClO} / 1 \mathrm{M} \mathrm{LiClO}, E_{-}=-0.3 \mathrm{~V}, E_{+}=+1.2 \mathrm{~V}$.

The results in Fig. 6 also show that $p H$ does not have a great influence upon the rate of hydrous oxide growth in $\mathrm{LiClO}_{4}$ solutions when $E_{-}=-1.4 \mathrm{~V}$ and $E_{+}=+1.6 \mathrm{~V}$. The data for acidic, neutral, and basic $\mathrm{LiClO}_{4}$ solutions fit the same curve.

Burke and Scannell (10) have reported that Ir oxide growth is slower in base than in acid. The present results contradict this and show that the overall solution composition, rather than just the $p H$, determines the Ir oxide growth rate.

Iridium oxide electrochemistry in neutral lithium perchlorate solutions. - The electrochemistry of Ir oxide in neutral $\mathrm{LiClO}_{4}$ is rather unusual and deserves further discussion. Figure 7 shows some voltammograms of Ir oxide (grown in $1 M \mathrm{LiClO}_{4} / 0.1 \mathrm{M} \mathrm{HClO}_{4}$ ) in neutral $1 M$ $\mathrm{LiClO}_{4}$. It should be noted that this oxide film is thinner than the one used in Fig. 2. Figure 7A shows the effect on the voltammogram of changing the potential limits of the scan. It can clearly be seen that the reduction peak at $-0.295 \mathrm{~V}$ is associated with the oxidation of the film at potentials of $\sim 0.7 \mathrm{~V}$ ( $\longrightarrow$ ). When the upper potential limit is maintained below the potential of this oxidation process $(\ldots$.$) , the reduction wave at -0.295 \mathrm{~V}$ is absent and a broad reversible wave is obtained at $-0.100 \mathrm{~V}$. When the lower potential limit is above $-0.295 \mathrm{~V}(\ldots)$, then the oxidation peak at $+0.595 \mathrm{~V}$ is absent.

Thus, there appear to be two major redox processes occurring in this solution, a reversible process occurring at $-0.100 \mathrm{~V}$ and an irreversible process centered at $\mathrm{ca}$. $+0.15 \mathrm{~V}$ (oxidation above $0.5 \mathrm{~V}$, reduction below $\sim-0.2 \mathrm{~V}$ ). This interpretation is supported by the effect of sweep rate $(s)$ on the voltammogram (Fig. 7B). Note that the current sensitivities $(S)$ were chosen so that $S / s$ is the same for each voltammogram. The position of the wave for the reversible process, seen in the anodic scan, is independent of the sweep rate and the peak currents increase linearly with the sweep rate, as expected for a surface process $(23)$. The oxidation and reduction peaks of the other major process shift to higher and lower potentials, respectively, as the scan rate is increased and the peak currents increase less than linearly with sweep rate. This indicates that a new process having different kinetics is now observed.

The cyclic voltammetry of Ir oxide in neutral $\mathrm{LiClO}_{4}$ can be explained if it is assumed that $\mathrm{Li}^{+}, \mathrm{H}^{+}$, and $\mathrm{OH}^{-}$ are all involved in the electrochemical reactions and that the oxidation and reduction processes occurring at $>0.5 \mathrm{~V}$ and $<-0.2 \mathrm{~V}$ are related to $\mathrm{pH}$ changes which oc- 


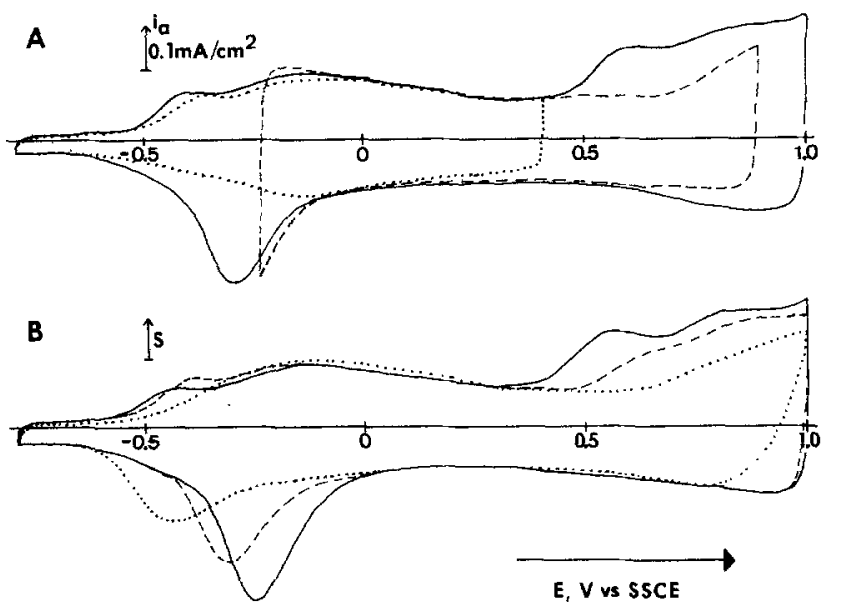

Fig. 7. Cyclic valtammograms of Ir oxide in $1 \mathrm{M} \mathrm{LiClO}_{4}(\mathrm{pH} \sim 6)$. A. Voltammograms at $100 \mathrm{mV} / \mathrm{s}$ with various potential limits. B. Voltammograms ot $0.02(-), 0.2(--)$, and $2(\cdots)) \mathrm{V} / \mathrm{s}$. S/scan rate $=$ $1\left(\mathrm{~mA} / \mathrm{cm}^{2}\right) /(\mathrm{V} / \mathrm{s})$.

cur within the oxide film with potential cycling in these neutral solutions $(2,10)$. As the oxide is oxidized, $\mathrm{H}^{+}$is generated $(18,22)$ and so the interior of the oxide becomes acidic. Hence, the oxidation of the oxide is seen at more positive potentials (ca. 0.4 to $1.0 \mathrm{~V}$ ), characteristic of Ir oxide oxidation in acidic media (Fig. 1). During reduction of the oxide, $\mathrm{H}^{+}$is consumed, and the main reduction wave is now seen at a potential $(-0.295 \mathrm{~V})$ that is characteristic of Ir oxide reduction in basic media (Fig. 3).

The reversible process occurring at ca. $-0.1 \mathrm{~V}$ does not appear to be affected by these $\mathrm{pH}$ changes and it is there fore likely that $\mathrm{Li}^{+}$is involved in the redox process in the $1 M \mathrm{LiClO}_{4}$ solution. Thus, it is proposed here that the oxidation peak at ca. $-0.1 \mathrm{~V}$ involves expulsion of $\mathrm{Li}^{+}$from the film and the reduction peak at ca. $-0.1 \mathrm{~V}$ [Fig. 7A $(\cdots \cdot)$ ] involves $\mathrm{Li}^{+}$insertion in to the Ir oxide. Further evidence for the $\mathrm{Li}^{+}$insertion/expulsion mechanism has been obtained from analysis of the ion content of the Ir oxide films (18), and has also been reported for Ir oxide films in $\mathrm{Li}^{+}$-containing 2 -methyl-tetrahydrofuran solu. tions (14).

\section{Conclusions}

Neutral aqueous $\mathrm{LiClO}_{4}$ solutions have been found to be superior to aqueous $\mathrm{H}_{2} \mathrm{SO}_{4}$ as a medium for the growth of hydrous Ir oxide films. Higher oxide growth rates can be achieved and less dissolution of the oxide occurs during growth in neutral $v s$. acidic growth media. Also, the resultant Ir oxide films have a greater mechani. cal stability and are probably less hydrated when $\mathrm{LiClO}_{4}$ is used, as compared to sulfuric acid grown films.

The empirical formula weight of the oxidized form of Ir oxide, grown in neutral $\mathrm{LiClO}_{4}$ and dried in air, was found to be $260 \pm 10$, indicative of an empirical formula of $\mathrm{IrO}_{2} \cdot 2 \mathrm{H}_{2} \mathrm{O}$. Vacuum drying reduced the formula weight to $230 \pm 10$, indicating dehydration to $\mathrm{IrO}_{2}$.
A useful parameter $\left(E_{n=1}\right)$, which indicates the potential at which one electron has been passed per Ir atom in an oxide film, has been determined in a number of the solutions in this work. This permits the accurate measurement of the quantity of Ir oxide film at an electrode surface from the cyclic voltammetric response.

\section{Acknowledgment}

The authors gratefully acknowledge financial support from the Natural Sciences and Engineering Research Council of Canada and from Allied Canada Incorporated.

Manuscript submitted Jan. 15, 1987; revised manuscript received July 2, 1987.

University of Calgary assisted in meeting the publication costs of this article.

\section{REFERENCES}

1. L. D. Burke, in "Electrodes of Conductive Metallic Oxides," Part A, S. Trasatti, Editor, Elsevier Publishing, New York (1980).

2. S. Gottesfeld and J. D. E. MeIntyre, This Journal, 126, 742 (1979)

3. J. D. E. McIntyre, W. F. Peck, and S. Nakahara, ibid., 127, 1264 (1980).

4. G. Beni, C. E. Rice, and J. L. Shay, ibid., 127, 1342 (1980).

5. J. Mozota and B. E. Conway, Electrochim. Acta., 28, 9 (1983).

6. L. D. Burke and D. P. Whelan, J. Electroanal. Chem., 162,121 (1984).

7. S. H. Glarum and J. H. Marshall, This Journal, 127, 1467 (1980).

8. S. Gottesfeld, ibid., 127, 1922 (1980).

9. J. Mozota and B. E. Conway, ibid., 128, 2142 (1981).

10. L. D. Burke and R. A. Scannell, J. Electroanal. Chem., 175,119 (1984).

11. P. G. Pickup and V. I. Birss, ibid., 220, 83 (1987).

12. D. N. Buckley, L. D. Burke, and J. K. Mulcahy, J. Chem. Soc. Faraday 1, 72, 1896 (1976).

13. D. Michell, D. A. J. Rand, and R. Woods, J. Electroanal. Chem., 84, 117 (1977).

14. J. D. E. McIntyre, S. Basu, W. F. Peck, Jr., W. L. Brown, and W. M. Augustyniak, Phys. Rev. B, 25, 7242 (1982).

15. R. Kotz, H. Neff, and S. Stucki, This Journal, 131, 72 (1984).

16. J. Augustynski, M. Koudelka, J. Sanchez, and B. E. Conway, J. Electroanal. Chem., 160, 233 (1984).

17. V. Birss, R. Myers, H. Angerstein-Kozlowska, and B. E. Conway, This Journal, 131, 1502 (1984).

18. P. G. Pickup and V. I. Birss, J. Electroanal. Chem., In press.

19. T. F. Anderson, Trans. N.Y. Acad. Sci., 13, 130 (1951).

20. S. S. Berman and W. A. E. McBryde, Analyst, 81, 566 (1956).

21. J. Mozota and B. E. Conway, Electrochim. Acta., 28, 1 (1983).

22. L. D. Burke, J. K. Mulcahy, and D. P. Whelan, J. Electroanal. Chem., 163, 117 (1984).

23. A. J. Bard and L. R. Faulkner, in "Electrochemical Methods, Fundamentals and Applications," p. 522, Wiley, New York (1980). 